\title{
Vibration perception in normal man and medical patients
}

\author{
GENEVIEVE D. GOFF, BURTON S. ROSNER ${ }^{1}$, THOMAS DETRE, AND \\ DAVID KENNARD
}

From Yale University School of Medicine, New Haven, Connecticut, U.S.A.

Interest in sensitivity to vibration as an aid to neurological diagnosis began in 1889 when Rumpf tested this function in a case of syringomyelia (Fox and Klemperer, 1942). Subsequent investigators found altered vibratory sensitivity in various disorders of the nervous system (e.g., Williamson, 1922). Reduced sensitivity, for example, has been reported in peripheral neuritis, diabetes mellitus, and pernicious anaemia (e.g., Cosh, 1953), while hypersensitivity has been seen in the Parkinsonian syndrome (Gordon, 1945). Changes in vibratory sensitivity have been used as positive or negative diagnostic indicators (e.g., Canelas, 1958).

Unfortunately, efforts to establish a simple, standard clinical routine for testing vibratory sensitivity have been plagued by a variety of problems. The first one concerns age and sex differences. Although vibratory sensitivity diminishes with ageing (e.g., Newman and Corbin, 1936; Laidlaw and Hamilton, 1937), few clinical investigations have allowed for this effect. This is quite surprising when one considers the high mean age of patients displaying certain clinical neurological symptoms. Possible sex differences also have been investigated (Mirsky, Futterman, and Broh-Kahn, 1953; Steiness, 1957; Detre, Feldman, Rosner, and Ferriter, 1962), but the results are inconclusive.

Many approaches to clinical testing of vibration also have suffered procedural difficulties, such as inadequate control of the stimulus or of the routine (see discussion in Steiness, 1957). In earlier investigations, furthermore, thresholds were measured at one or, at most, a few frequencies. Since vibratory thresholds are a U-shaped function of frequency (Goff, 1959), measurements at one frequency give much less information than is necessary to assess vibratory functions. Attempts to secure more clinically sensitive tests of vibratory sensitivity have prompted introduction of such techniques as the use of a pneumatic cuff (Steiness, 1959), the in-

${ }^{1}$ Present Address: Department of Psychiatry, University of Pennsylvania School of Medicine, Philadelphia, Pennsylvania. duction of nerve blocks and ischaemia (Cosh, 1953), and study of adaptation or 'fatigue' (Frohring, Kohn, Bosma, and Toomey, 1945). These methods possess various disadvantages. The subject is exposed to discomfort; he must often concentrate for extended periods; the testing period becomes lengthy; the investigator must be highly trained; and the subject and investigator often become involved in an emotionally charged interaction.

Detre et al. (1962) recently described a method for measuring vibratory thresholds which seems to avoid the procedural problems enumerated above. The method is based on Békésy's (1947) selfrecording audiometer. Békésy (1960) had already used the device for vibratory studies. With this method, delivery of the stimulus is standardized and sensitivity is tested at many frequencies. The subject and investigator interact minimally. Further, the subject experiences no discomfort or inconvenience during the 10-minute testing period; this short time minimizes fatigue; a minimum of concentration, intelligence, and verbal ability are required of the subject; and the experimenter does not need extensive training.

Detre et al. (1962) reported significant differences in vibration perception between normal subjects and acute psychotics. In contrast, audiograms on normal and schizophrenic subjects did not differ over the same frequency range used for vibratory tests. These controls showed that the results on vibration were modality-specific and were not an artifact of the Békésy method of stimuli presentation; they were not produced by the subject's failure to understand directions or pay attention to the task.

The present study then was designed to accomplish three further aims: (1) to evaluate further Békésy's technique by investigating the reliability of the measurements and the possible learning or practice effects; (2) to establish adequate age and sex norms by testing a large normal population; and (3) to investigate patients with organic diseases in comparison with such norms. Achievement of these 
aims is prerequisite to a sound clinical routine for testing vibratory sensitivity.

\section{METHODS}

APPARATUS AND PROCEDURE Previous studies (Gregg, 1951; Cosh, 1953; Wilska, 1954) showed that the fingers yield more reliable and more sensitive vibratory thresholds than do other parts of the body. Therefore, the site of stimulation selected was the index finger and both left and right index fingers were compared. Prior investigators (e.g. Gregg, 1951) also found that heavy pressure on the vibrator causes damping effects and that too light pressure does not yield adequate contact. They noted that the influence of pressure on the threshold is negligible as long as these two extremes are avoided. To assure that the applied force would be kept within acceptable limits, the apparatus described by Detre et al. (1962) was modified by mounting the vibrator on a lever balanced against a weight damped in an oil bath. This forced the subject to apply a minimum pressure in order to keep his finger on the vibrator. The experimenter could observe excessive movement of the lever if too much pressure was applied.

The subject sat in a comfortable chair with one arm resting upon the flat surface of the console containing the vibratory apparatus. The index finger being tested rested upon a stylus which delivered the stimulus. The subject held a response switch in his other hand. With the Békésy technique the subject determined his own threshold by pressing the response switch to increase intensity if he did not feel the stimulus and releasing the switch to decrease intensity if he did feel it. An oscillator with a motor driven frequency control continuously changed the vibratory frequency from 35 c.p.s. to 600 c.p.s. TheD fluctuations in stimulus intensity produced by operation of the response switch were automatically plotted as ap function of the logarithmically changing vibrator fre quency. The resulting 'vibrogram' therefore represents theo subject's successive vibratory threshold crossings and his variability around threshold over the frequency range tested. Figure 1 shows a sample vibrogram.

Subjects were instructed: 'This is a simple test to finc out how well you feel a moving object with your finger:tip. Place the tip of your left (right) index finger on topes of this little rod. Hold this switch in your right (lefto hand. All you have to do is press the switch with youE right hand as soon as you feel the rod vibrating an release it as soon as you do not feel the rod vibrating Concentrate on the feeling in the tip of your finger. FirsD we'll let you practice.' The subject was allowed to practice्s about a minute with the oscillator held at 50 c.p.s Instructions were repeated if necessary. The oscillator then was set at 35 c.p.s. The motor drive was engaged to $\vec{a}$ raise the frequency gradually and the subject was informed that the test was starting. The test ended about four minutes later when the frequency of vibration had reacheof 600 c.p.s. As a control to ensure that the subject was responding only to the vibratory stimulus, the vibratopo could be turned off without the subject's knowledge. IP the subject continued to respond, instructions and practice were repeated. Audiograms could also be obtained (witho instructions reworded appropriately) by simply $\mathrm{m}=$ plugging the vibrator, plugging in a set of earphores, and making an adjustment of the output amplifier.

\section{FREQUENCY (cPS)}

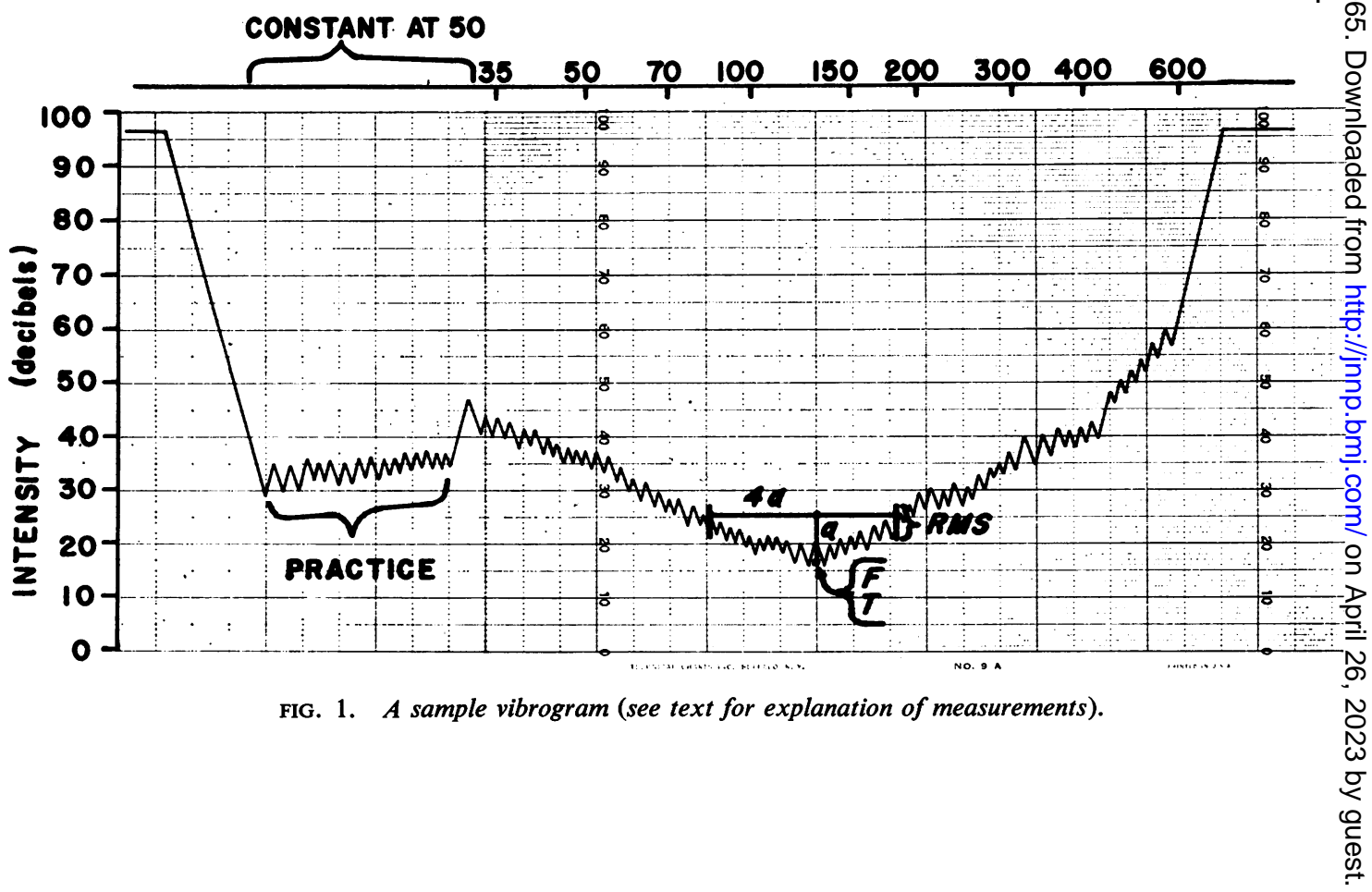


SUBJECTS Four hundred and fifty-one normal subjects were tested, ranging in age from 10 to 72, with great diversification of social background. Subjects included public and private school children, private university and state college students, employees of two large urban companies (ranging from top executives to labourers), housewives, and various others. Thirteen subjects were eliminated because of outside disruptions of the testing situation or because of inability to follow directions. Patients were secured from the Psychiatric Division and from the outpatient clinics of the Yale-New Haven Medical Centre.

DATA ANALYSIS Detre et al. (1962) quantified the vibrogram by determining the mean threshold at each of 11 frequencies. They connected these 11 values to obtain a U-shaped curve for each subject. Rather than determine the mean of the upper and lower limits of the vibrogram at any desired frequency, it is easier simply to read the intensity value at that frequency regardless of where it falls on an ascending or descending excursion. In this study intensity values were measured in this manner at various frequencies along the vibrogram. Two methods of analysis then were used. First, for a particular group of subjects the means of the intensities at eight selected frequencies $(50,70,100,150,200,300,400$, and 600) were plotted to yield a U-shaped vibratory sensitivity curve (Fig. 2). This method of analysis is cumbersome when many age groups are being studied. Furthermore, it permits comparisons only of threshold values, although patients may also differ from normals in variability (Steiness, 1957). Consequently, a more refined method of data analysis was devised, based on the observation that a normal vibrogram approximates a parabola as a function of the square root of frequency. Intensity values at as many as $\mathbf{4 0}$ points along the vibrogram were reduced with this method by a digital computer to four basic measurements: $F$, the frequency at which the subject is most sensitive; $\mathrm{T}$, the threshold at that frequency; $4 \mathrm{a}$, a measure of the shape of the curve, i.e., the width of the

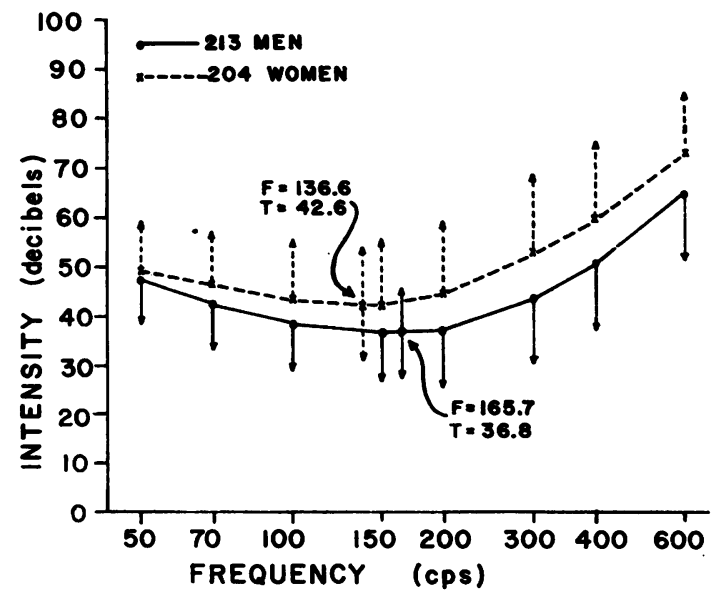

FIG. 2. Vibratory sensitivity curves for normal men and women. best fitting parabola; and RMS, a measure of the variability. These four measurements are illustrated in Figure 1. (Fortran listing for the computer programme is available.)

\section{RESULTS}

NORMAL DATA ANALYSIS Eight normal subjects were each tested from five to eight times over a twomonth span of time. The results verified the intrasubject stability of the vibratory measurements. As a futher check, 60 normal subjects were tested on both hands. Half the subjects had the right hand tested first; half had the left hand first. Analysis of variance and $t$ tests showed no hand difference and no effect with practice. There was a small, insignificant tendency for the left hand to benefit more by practice than the right. Also, as several investigators have reported, the left hand is slightly more sensitive than the right; again, the difference was not significant.

Fifteen of the 438 normal subjects who provided vibrograms $(3.5 \%)$ gave curves which could not be fitted by the parabolic function. Six other subjects were excluded as having grossly abnormal records, although the computed values of the parameters were not actually impossible. All statistics reported below are from the remaining 417 normal subjects.

Figure 2 shows the vibratory sensitivity curves for men and women. The arrows indicate plus 1 S.D. for the women and minus 1 S.D. for the men. The variability is greater than that reported by other investigators since our method of measurement does not exclude intra-subject variability. Student's t test showed highly significant sex differences $(P<0.001)$ at all points but 50 c.p.s. $(P<0 \cdot 10)$. In Fig. 2 the $T$ (threshold) and $\mathrm{F}$ (frequency) values also have been combined for each sex to establish mean points, with \pm 1 S.D. for threshold indicated by arrows. These two measures duplicate information secured by the first method of analysis. Student's $t$ test yielded highly significant sex differences $(P<0.001)$ for both $T$ and $F$. Thus, both methods of analysis show that men have lower vibratory thresholds than women. The frequency of greatest sensitivity also is lower in women than in men. The other two computed parameters, $4 \mathrm{a}$ and RMS, did not yield a sex difference. Furthermore, all analyses with these parameters in normal subjects were negative and thus are not described further. In order to study the effects of age on $T$ and $F$, our 417 subjects were subdivided into seven age groups: 10-14, 15-19, 20-24, 25-34, 35-44, 45-54, and 55-72 years. As expected, analysis of variance showed sex to be highly significant $(P<0.001)$ for both $T$ and $F$. The analysis also revealed that age was significant $(P<0.01)$ for $F$. 
To determine the effect of age alone, individual $t$ tests were done on $T$ and $F$ between age groups within a sex. This analysis revealed that the youngest two groups of women did not differ and so could be combined into one group (Y). The remaining female subjects could be divided into a middle age group (M) and an older group (O). Data for males could be grouped in a similar manner. The mean $F$ and $T$ values for these three age groups are presented in Table I. The table also shows the significance levels of $t$ tests between the age groups. There are no significant differences between the young and middleage groups of men and no differences between the middle and old-age groups of women.

\section{TABLE I}

MEAN FREQUENCY AND THRESHOLD VALUES FOR DIFFERENT AGE GROUPS

\begin{tabular}{|c|c|c|c|c|c|c|}
\hline \multirow[b]{2}{*}{ Age Groups } & \multicolumn{3}{|l|}{ Men } & \multicolumn{3}{|c|}{ Women } \\
\hline & No. & $\boldsymbol{F}$ & $T$ & No. & $\boldsymbol{F}$ & $T$ \\
\hline $\begin{array}{ll}Y & (10-19) \\
M & (20-44) \\
O & (45-72)\end{array}$ & $\begin{array}{r}51 \\
123 \\
39\end{array}$ & $\begin{array}{l}164 \cdot 5 \\
169 \cdot 6 \\
154 \cdot 8\end{array}$ & $\begin{array}{l}35 \cdot 2 \\
36 \cdot 4 \\
40 \cdot 0\end{array}$ & $\begin{array}{r}46 \\
116 \\
42\end{array}$ & $\begin{array}{l}156 \cdot 1 \\
132 \cdot 0 \\
128 \cdot 2\end{array}$ & $\begin{array}{l}41 \cdot 5 \\
43 \cdot 1 \\
42 \cdot 4\end{array}$ \\
\hline
\end{tabular}

Significance levels of $t$ tests between age groups

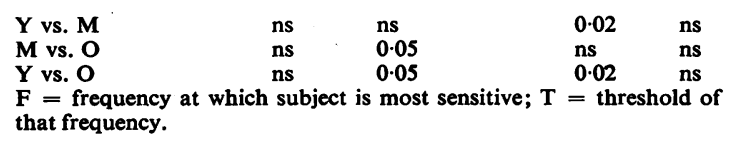

Vibratory sensitivity curves for these three age groups appear in Fig. 3 and $t$ tests between the three age groups at each of the eight frequencies confirmed the above findings. Neither the younger two age groups of men nor the older two age groups of women differed among themselves. Accordingly, $\frac{\text { o }}{z}$ data for the younger two groups of men were combined and compared with those for the oldest group. For women, data from the older two groups weree combined and compared with those from the young est group. Results of these analyses are given in Table II. The findings show that the effect of age in men is to raise the threshold. No significant? change occurs in F, but the whole threshold curve is elevated at all frequencies. In women the effect of age is different: there is a significant decrease in $\overrightarrow{F_{0}^{*}}$ but no change in $\mathrm{T}$. This is consistent with the analysis of the vibratory sensitivity curves, which indicates that women undergo no change with age at lower $\overline{\bar{c}}$. frequencies but show increased thresholds at higher frequencies.

In summary, our normal population displays ${ }^{£}$ definite sex and age differences. Men have lowero $\vec{\circ}$ vibratory thresholds and a higher frequency for $\overrightarrow{ }$ maximum sensitivity than women. The effect of age $\omega$ in men is to raise the threshold curve at all fre-s quencies. In women aging produces increased? thresholds for higher frequencies only, which resultsi in a lowering of the frequency showing the greatest $\%$ sensitivity.

ANALYSIS OF DATA FROM PATIENTS VibrogranRs $\triangle$ were collected from 85 patients in four diagnos ${ }_{1}^{-}$ categories (organic brain syndrome, seizures, dia- $D$ betes mellitus, and pernicious anaemia). Fourteen $\mathbb{\Phi}$ patients $(16.5 \%)$ gave vibrograms whose shape weis too deviant for fitting by a parabolic function. The remaining 71 patients were subdivided by sex and $\vec{\varphi}$ the age groupings found to be fruitful in the normalo population. Cells containing fewer than four sub-

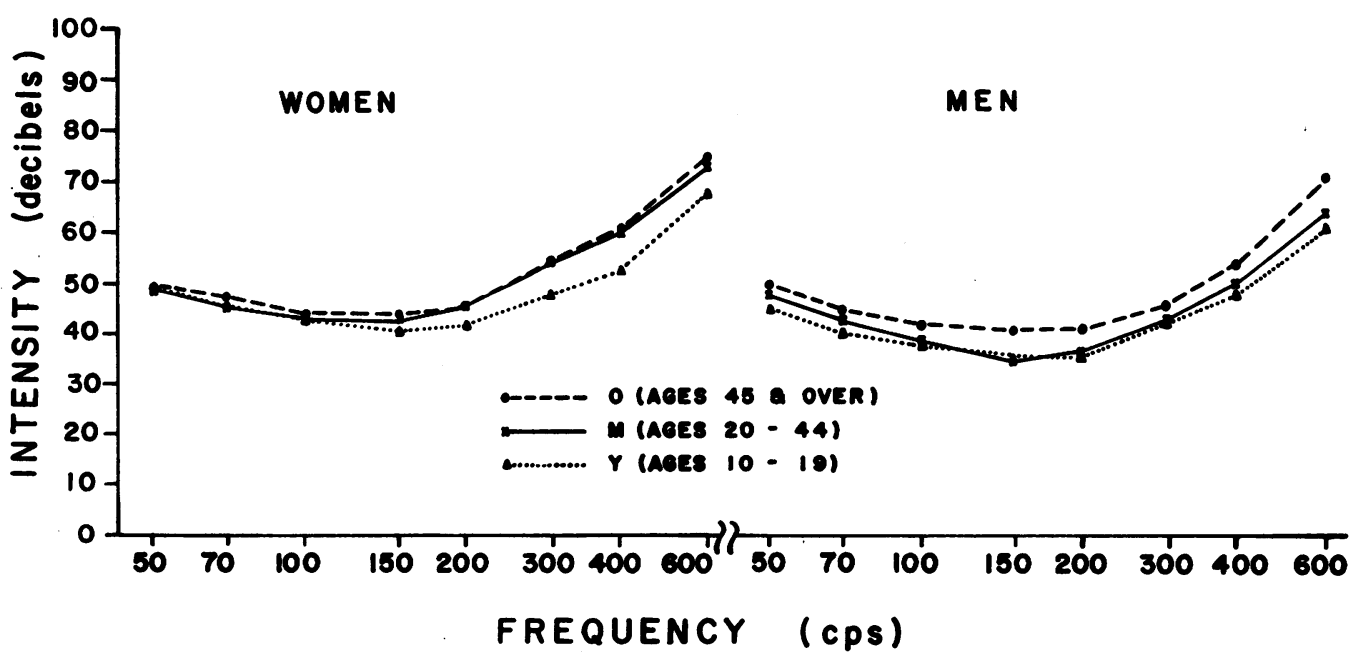

FIG. 3. Vibratory sensitivity curves of three age groups of normal men and women. 
TABLE II

MEAN FREQUENCY AND THRESHOLD VALUES FOR COMBINED AGE GROUPS AND SIGNIFICANCE LEVELS OF T TESTS

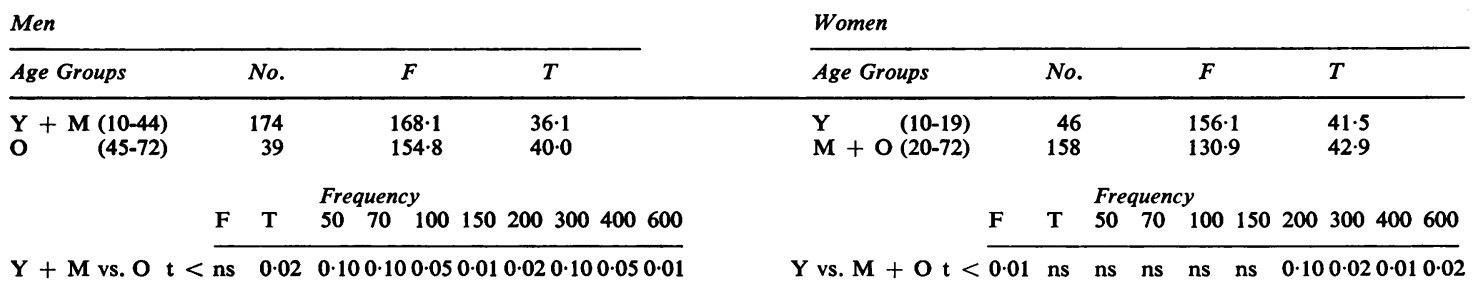

$\mathbf{F}=$ frequency at which subject is most sensitive; $T=$ threshold of that frequency

jects were then eliminated. Age, sex, and diagnostic distributions for the remaining 65 subjects appear in Table III.

\section{TABLE III}

AGE AND SEX DISTRIBUTION FOR PATIENTS

\begin{tabular}{|c|c|c|c|c|}
\hline \multirow[b]{2}{*}{ Diagnostic Group } & \multicolumn{2}{|l|}{ Men } & \multicolumn{2}{|l|}{ Women } \\
\hline & $\begin{array}{l}\text { Younger } \\
(10-44)\end{array}$ & $\begin{array}{l}\text { Older } \\
\text { (over 45) }\end{array}$ & $\begin{array}{l}\text { Younger } \\
(10-19)\end{array}$ & $\begin{array}{l}\text { Older } \\
\text { (over 20) }\end{array}$ \\
\hline Organic brain syndrome & 8 & - & - & 13 \\
\hline Seizures & 7 & - & 9 & 15 \\
\hline Diabetes mellitus & - & - & - & 4 \\
\hline Pernicious anaemia & - & 4 & - & 5 \\
\hline
\end{tabular}

Figure 4 shows vibratory sensitivity curves for the four patient groups and for the normal population. Ages and sexes have been combined for display purposes. Several points below 100 c.p.s. are omitted, since patients examined early in the study had not been tested at lower frequencies.

Since only eight of the 16 cells in Table III contain more than four subjects, analysis of the effects of age

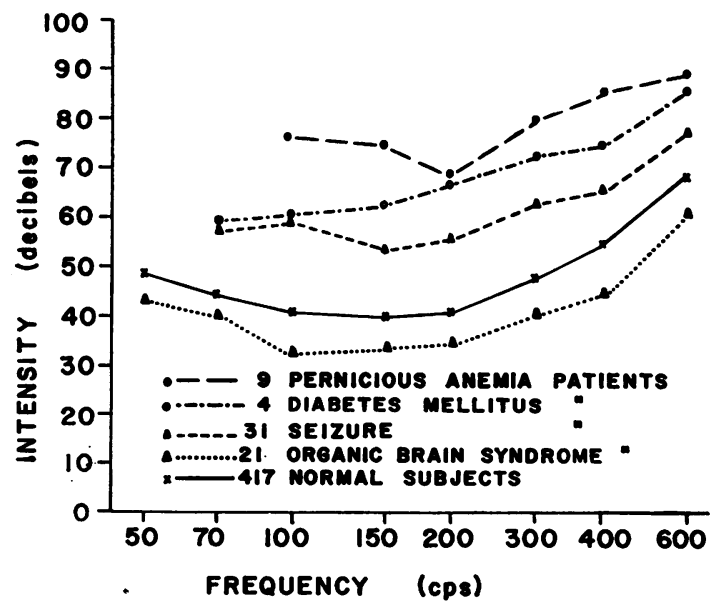

FIG. 4. Vibratory sensitivity curves for four patient groups and normals. or sex in patients could not be completed. Each of these eight groups of patients was compared with the corresponding age-sex normal group and with any other patient group of the same age and sex. Two parameters, F and 4a, each yielded only one significant difference among the 15 comparisons made. Neither difference was highly significant. We conclude that patients do not differ from normals in these two measurements.

The means and standard deviations for $T$ and RMS and results of $t$ tests are given in Table IV. No significant difference in RMS values was found in seven comparisons between patient groups. However, significant differences were found in RMS values in eight comparisons of normal and patient groups. Five of these were highly significant. Thus, patients are more variable than normal subjects. A more complex pattern emerged in considering threshold values. The comparisons between patient groups showed that those with organic disease have significantly lower vibratory thresholds than other patients. However, the other three patient groups do not differ among themselves. Comparisons of the patient groups with the appropriate normal groups showed that six of the eight patient groups have significantly different thresholds from normal. The two classes of patients who show normal Ts are the young males with organic disease and the young female seizure patients.

\section{DISCUSSION}

This study of vibration sensitivity in a population of 417 normal subjects indicates that men have lower vibratory thresholds than women for the index finger. These findings contrast with those of Steiness (1957) who reported no differences between sexes in 100 subjects tested on the index finger but higher thresholds for men than for women on the big toe. Steiness, however, used a stimulus of 100 c.p.s. and, as Fig. 2 shows, sex differences are smaller at 100 c.p.s. than at higher frequencies. Therefore, his smaller sample and his procedure probably explain the lack of a significant difference between sexes 
TABLE IV

MEAN T AND RMS VALUES AND RESULTS OF T TESTS FOR VARIOUS SEX AND AGE GROUPS

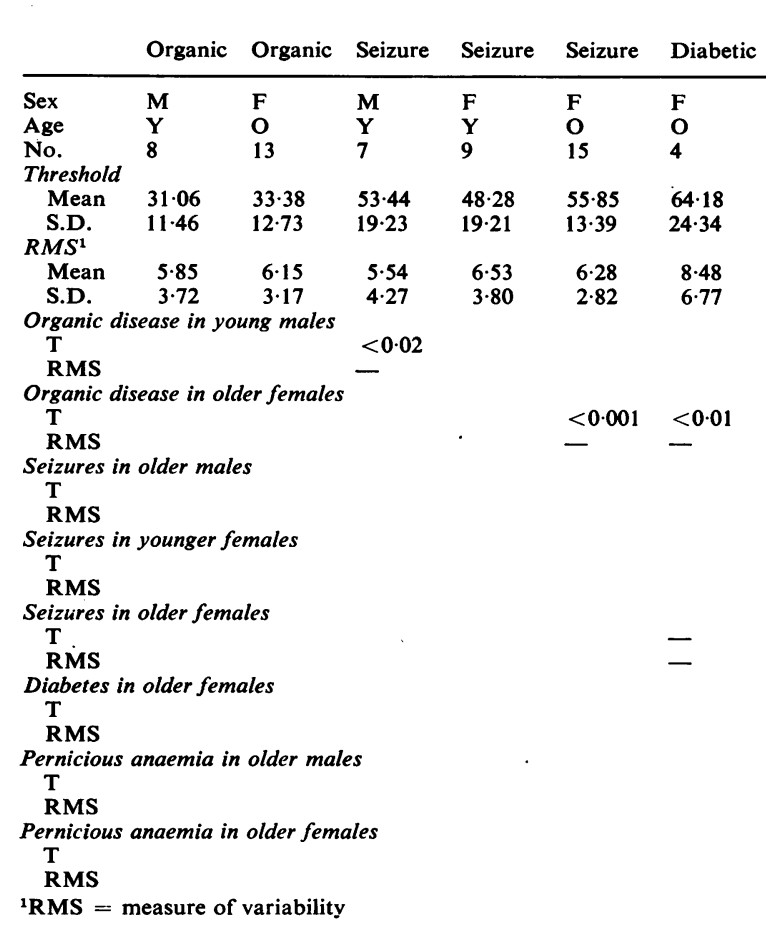

Pernicious Pernicious

Anaemia Anaemia Normal Normal Normal Normal

$\begin{array}{lll}\mathbf{O} & \\ 4 & & \end{array}$

45

76.50 $72 \cdot 24$

$13.34 \quad 21.98$

$Y$

\section{$5 \cdot 38$}

0.08

$8 \cdot 74$

$4 \cdot 28$

$\begin{array}{llll}\text { M } & \text { F } & \text { M } & \text { F } \\ \text { Y } & \text { Y } & \text { O } & \text { O } \\ 174 & 46 & 39 & 158 \\ 36.07 & 41.49 & 39.97 & 42.88 \\ 9.02 & 10.10 & 10.84 & 11.86 \\ & & & \\ 3.96 & 3.73 & 3.66 & 3.98 \\ 1.41 & 1.24 & 1.63 & 1.38\end{array}$

$\overline{<0.01}$

$<0.001$

$<0.01$

$<0.001$

$<0.001$
$<0.02$

$<0.001 \quad$


$<0.001$
$<0.001$

$<0.001$
$<0.001$

for vibratory thresholds on the index finger. His results for the big toe could reflect the known phenomenon of reduced sensitivity in lower limbs in men due to increased circulatory problems.

Many studies have reported rises in vibratory threshold with age, but no previous study had analyzed how this change interacts with sex difference. The vibrogram of men remains stable until after age 45 and then the entire curve rises. Women's vibrograms are stable only through the teens; thereafter, sensitivity remains constant at the lower frequencies but rises at the higher frequencies. This pattern of threshold changes in women is similar to generally reported effects of age on the audiogram.

Previous investigators have reported no sex differences for patient groups (e.g., Detre, Rosner, Feldman, and Ferriter, 1964), but many have observed the rise in threshold with age. The patient groups tested in this study were too small to permit an analysis of age and sex, although the trend is for the same age differences reported for the normal group. The higher variability in individual patients as against normals may have obscured any real sex differences in patients.

Although the Békésy method seems a reliable and clinically promising test of vibration, analysis of the

resulting curves merits further attention. The vibrograms of $16.5 \%$ of the patients tested could not be fitted to a parabola. Since only $3.5 \%$ of the normals had such deviant vibrograms, patients' curves may differ from those of normals (and perhaps from each other) in some aspects which our analysis does not tap. Visual inspection of the vibrograms suggests such possibilities as curves which are flat over a wide range of frequencies without necessarily showing a locus of maximum sensitivity or curves in which the two arms of the 'parabola' have quite different slopes. The RMS value in this study is an average measure of the variability throughout the frequency range. Measures of variability as a function of frequency also should be investigated, since some patients are more variable at higher than at lower frequencies. Another possibility for future study is a parameter used by Jerger and Herer (1961) for audition. They found that a comparison between thresholds for interrupted stimulation and for continuous stimulation distinguished between organic and non-organic hearing loss.

\section{SUMMARY}

The vibrogram technique based on the Békésy 
audiometer yields reliable measures of vibratory sensitivity. It has many advantages over older techniques. Results from 417 normal subjects tested on the left index finger showed that men have lower vibratory thresholds than women. There was an elevation of the vibrograms with age. Men older than 45 years of age suffer a general rise in the threshold curve at all frequencies. In women the effect of age is to increase the thresholds at higher frequencies after 20 years of age, with little change at the lower frequencies. Patients with various neurological and metabolic problems showed greater variability in threshold than the normal population. Patients with pernicious anemia, diabetes, or seizures tended to have thresholds significantly higher than normal. The only difference between patient groups was the significantly lower thresholds of those with organic brain syndrome.

Support for this study was provided by grant MH-07300 from the National Institutes of Health, United States Public Health Service. The Grason-Stadler Company, Inc., West Concord, Massachusetts, designed and constructed the apparatus used in this study.

\section{REFERENCES}

Békésy, G. v. (1947). A new audiometer. Acta oto-laryng. (Stockh.), 35, $411-422$.

(1960). Experiments in hearing. McGraw-Hill, New York.

Canelas, H. M. (1958). Sensibilidade vibratória. Valor semiótico em algumas afecçkes do sistema nervoso. Arch. Neuro-psiquiat. (S. Paulo)., 16, 275-352.
Cosh, J. A. (1953). Studies on the nature of vibration sense. Clin. Sci., 12, 131-151.

Detre, T., Feldman, R. G., Rosner, B. S., and Ferriter, C. (1962). Vibration perception in normal and schizophrenic subjects. J. Neuropsychiat., 3, suppl. 1, pp. 145-150.

—, Rosner, B. S., Feldman, R. G., and Ferriter, C. (1964). Effects of fluphenazine on vibration perception in seizure disorders. Neuropsychopharmacology, 3, 72-76.

Fox, J. C., and Klemperer, W. W. (1942). Vibratory sensibility: a quantitative study of its thresholds in nervous disorders. Arch. Neurol. Psychiat. (Chic.), 48, 622-645.

Frohring, W. O., Kohn, P. M., Bosma, J. F., and Toomey, J. A. (1945). Changes in the vibratory sense of patients with poliomyelitis as measured by the pallesthesiometer. Amer. J. Dis. Child., 69, 89-91.

Goff, G. D. (1959). Differential discrimination of frequency of cutaneous mechanical vibration. Unpublished dissertation, Universit. of Virginia.

Gordon, A. (1945). 'Vibration sense' as a differential diagnostic sign in doubtful cases of parkinsonian syndrome. J. nerv. ment. Dis., 101, 589-590.

Gregg, E. C. (1951). Absolute measurement of the vibratory threshold. Arch. Neurol. Psychiat. (Chic.), 66, 403-411.

Jerger, J., and Herer, G. (1961). Unexpected dividend in Békésy audiometry. J. Speech Dis., 26, 390-391.

Laidlaw, R. W., and Hamilton, M. A. (1937). Thresholds of vibratory sensibility as determined by the pallesthesiometer: A study of sixty normal subjects. Bull. neurol. Inst. N.Y., 6, 494-503.

Mirsky, I. A., Futterman, P., and Broh-Kahn, R. H. (1953). The quantitative measurement of vibratory perception in subjects with and without diabetes mellitus. J. Lab. clin. Med., 41, 221-235.

Newman, H. W., and Corbin, K. B. (1936). Quantitative determination of vibratory sensibility. Proc. Soc. exp. Biol. (N.Y.), 35, 273-276.

Steiness, I. (1957). Vibratory perception in normal subjects; vibratory perception in diabetics; a biothesiometric study. Acta med. scand., 158, 315-335.

- (1959). Vibratory perception in diabetics during arrested blood flow to the limb. Ibid., 163, 195-205.

Williamson, R. T. (1922). The vibrating sensation in diseases of the nervous system. Amer. J. med. Sci., 164, 715-727.

Wilska, A. (1954). On the vibrational sensitivity in different regions of the body surface. Acta physiol. scand., 31, 285-289. 